\title{
Nicbolas of Autrecourt and William of Ockbam on Atomism, Nominalism, and the Ontology of Motion
}

\author{
BLAKE D. DUTTON
}

Georgia State University

Nicholas of Autrecourt has been of interest to scholars primarily because of his place within the skeptical currents of fourteenth-century philosophy. However, just as there has been no general agreement about the nature of late medieval skepticism, there has been no agreement about where to locate Nicholas within it. Following Gilson's charge that Nicholas's attempt to dismantle Aristotelianism was a consequence of skeptical tendencies in Ockham's epistemology, ${ }^{1}$ much debate has focused on Nicholas's criterion of evident knowledge and its relation to Ockham's doctrine of the intuitive cognition of nonexistents. ${ }^{2}$ But while this debate is as fascinating as it is important, it has had the unfortunate consequence of leading commentators to ignore other aspects of Nicholas's thought which are well deserving of attention. This is particularly true in the case of his treatment of motion. In reducing all change to the locomotion of atoms, in positing an interstitial void, and in denying the infinite divisibility of the continuum, Nicholas both challenged Aristotelian physics at its most fundamental level and separated himself from virtually all of his scholastic

I would like to thank Norman Kretzmann, Steve Strange, and Stephen Brown for their helpful comments on various aspects of this article.

1. For Gilson's treatment of Ockham and Nicholas, see Etienne Gilson, The Unity of Philosophical Experience (New York: Scribner, 1937), pp. 61-103.

2. See the debate between Philotheus Boehner, who argues, contra Gilson, that Ockham's doctrine is antiskeptical, and Anton Pegis, who defends Gilson's reading. Philotheus Boehner, "The Notitia Intuitiva of Non-existents According to William of Ockham," in Traditio 1 (1943): 223-75; and Anton Pegis, "Concerning William of Ockham," in Traditio 2 (1944): 465-80. For a discussion of Nicholas's place vis-à-vis Ockhamism, see Ernest A. Moody, "Ockham, Buridan, and Nicholas of Autrecourt," Franciscan Studies 7:2 (June 1947): 127-60; and T. K. Scott, Jr., "Nicholas of Autrecourt, Buridan and Ockhamism," Journal of the History of Philosophy 9 (1971): 15-41. 
contemporaries. Yet with few exceptions, this has received virtually no attention. ${ }^{3}$

In what follows I wish to take some small steps toward rectifying this situation. My point of departure shall be to examine how Nicholas was forced to address the question of the ontological status of motion in an attempt to solve problems with the centerpiece of his anti-Aristotelian critique, namely, his doctrine of the eternity of all things. This is of interest because questions concerning the ontology of motion were generated from tensions which the scholastics perceived to exist among Aristotle's diverse statements concerning the relation of motion to the categories. The medieval debate over the ontology of motion, then, was a dispute among scholastics of different stripes who shared a common Aristotelian framework. Nicholas, however, abandoned this framework, adopted an atomistic theory of matter and altogether dispensed with Aristotle's definition and classification of motion. Nevertheless, he felt it necessary to weigh in on this issue. I shall explain why this was so and argue that it was in Ockham's nominalistic analysis of motion that Nicholas found the key to resolving problems in his own critique of Aristotle. Thus, despite Ockham's stated intention of correcting those errors destructive of Aristotelian philosophy, Nicholas was able to use his work in what was one of the most rabid anti-Aristotelian programs ever to arise in the Middle Ages.

Of course, all of this is of great importance for determining the impact of Ockhamism on the course of late scholastic thought, especially for evaluating its alleged corrosive influence. But it also raises questions about the relation of nominalism to atomism generally. In reflecting on Nicholas's use of Ockham it becomes clear that nominalism, insofar as it is driven by a concern to limit the kinds of entities which are postulated as corresponding to (categorematic) terms, ${ }^{4}$ provides a semantic and ontological analysis

3. The only comprehensive study of Nicholas's work is Julius R. Weinberg, Nicholaus of Autrecourt: A Study in 14th Century Thought (Princeton, N.J.: Princeton University Press, 1948). For Weinberg's treatment of Nicholas's views on motion, see chap. 10, pp. 163-74. For a short general survey of Nicholas's thought, see J. Reginald O'Donnell, "The Philosophy of Nicholas of Autrecourt," Mediaeval Studies 4 (1942): 97-125. The reader may also wish to consult Edward Grant, Much Ado about Nothing (Cambridge: Cambridge University Press, 1981), pp. 74-77, for a brief discussion of Nicholas's views on the vacuum.

4. Here I am indebted to Calvin Normore, who has analyzed the way in which the appellations nominales and nominalistae were used in the twelfth through the fifteenth centuries. He has shown that nominalism, as understood by the medievals themselves, was not so much a doctrine about universals as it was a doctrine about the truth conditions of sentences, particularly the kinds of entities which must be postulated as corresponding to the categorematic terms of a sentence in order to render it true. According to Normore, the medievals understood the division between realists and nominalists with respect to this issue to be a division between those who multiply entities as they multiply terms and those who restrict the multiplication of entities as far as possible. See Calvin Normore, "The Tradition of Medieval Nominalism," in Studies in Medieval Philosophy, ed. John Wippel (Washington D.C.: Catholic University of America Press, 1987), pp. 201-17. 
which lends atomism both greater coherence and completeness. As we shall see, atomism demands not only a nominalistic account of motion but also a nominalistic account of both the microproperties of atoms and the macroproperties of material bodies. If I am correct in this thesis, Nicholas's alignment with Ockham will appear to be motivated not simply by the need to solve problems associated with the doctrine of the eternity of things but also by his recognition of the philosophical kinship which exists between these seemingly disparate positions. ${ }^{5}$

\section{THE ETERNITY OF THE WORLD AND THE PROBLEM OF MOTION}

Nicholas begins his treatise Exigit ordo executionis by lamenting the fact that some men have spent thirty or more years studying the works of Aristotle and have learned no more than what could be learned in a very short time by a direct study of nature. ${ }^{6} \mathrm{He}$ complains that this excessive attention to ancient writings has turned men away from that life of charity and concern for the common good which is the duty of every Christian. To remedy this situation, he proposes to show that the purported conclusions of Aristotle have not been demonstrated and that, in almost every case, opinions opposed to these conclusions can be shown to be more probable. To this end he puts forth his own doctrine of the eternity of all things as a direct challenge to Aristotelian natural philosophy. ${ }^{7}$

5. I say this despite the fact that Ockham expended a great deal of energy in attempting to refute indivisibilism. Like most fourteenth-century opponents of indivisibilism, however, Ockham was not primarily concerned with physical indivisibilism (the position which Nicholas held) but with mathematical indivisibilism. This latter form of indivisibilism was developed in the context of solving problems associated with the composition of continua, both spatial and temporal, and thus dealt with such entities as points, lines, surfaces, and instants rather than with the material atoms of Democritus or Epicurus. For an excellent overview of Ockham's position on mathematical indivisibilism, see John E. Murdoch, "William of Ockham and the Logic of Infinity and Continuity," in Infinity and Continuity in Ancient and Medieval Thought, ed. Norman Kretzmann (Ithaca, N.Y.: Cornell University Press, 1982), pp. 165-206.

6. For a Latin text of the Exigit ordo executionis, see J. Reginald O'Donnell, "Nicholas of Autrecourt," Mediaeval Studies 1 (1939): 179-280. Translations from this and all other Latin texts cited in this article are my own. I am following O'Donnell's pagination.

7. Here we should note that in the propositions Nicholas puts forth concerning the eternity of all things, atomism and motion are not intended as demonstrated conclusions but as propositions having greater probability than the conclusions of Aristotle. Nicholas's aim, then, is not so much to build a new philosophical system as it is to break the grip of Aristotelianism on the minds of his contemporaries so that they may turn to more fruitful pursuits. 
The central thesis of this doctrine can be stated quite simply. Because of the unique contribution which each thing $(r e s)^{8}$ makes to the total and, of necessity, unvarying degree of perfection in the universe, everything is eternal and neither comes into being nor passes out of being. In Aristotelian terms, there is no generation or corruption in the universe, and though there is motion, it is such that it involves no acquisition or loss of being. In short, there is no passage whatsoever from nonbeing to being or from being to nonbeing among things.

In the course of elaborating and defending this thesis, Nicholas finds himself faced with the problem of reconciling it with the common experience of humanity. 9 The problem is this: the assertion that there is no generation or corruption in the universe seems to run afoul of our common experience since it is most certainly within our experience that things come into and pass out of being. I now see the color white in some object, but then I cease to see it as the object becomes black. Is it not the case, then, that there is at least one thing - this particular whiteness-that my experience tells me has ceased to exist and, hence, is not eternal? And could not examples such as this be multiplied indefinitely?

In answering this objection, Nicholas points out that the inference from the cessation of the appearance of whiteness to the cessation of its existence can be made only on the following assumption: everything which previously appeared to a sense but now does not appear, no matter what place the sense directs its gaze upon, no longer exists. ${ }^{10}$ Nicholas contends, however, that this assumption is indefensible since there are several explanations which might account for the cessation of the appearance of whiteness

8. Certainly Nicholas means to apply the term 'thing' (res) to whatever has real being, but he never specifies what it is that has real being. We might infer from the fact that all of the examples he cites while expounding the eternity doctrine are examples of substances and certain kinds of qualities that Nicholas follows Ockham in holding these alone to be real. As we shall see, however, Nicholas's ontology was not Aristotelian but atomistic. Hence, it may be that the term 'thing' is primarily applicable to atoms themselves. See $\mathbf{n} .15$ for further discussion.

9. I am focusing on this objection rather than the proof for the eternity doctrine because it is in the course of answering it that the problem of the ontological status of motion arises. We might take note, however, of the following adumbration of the central proof for the eternity doctrine which Nicholas gives in the Exigit: "Everything whose present existence is for the good ... of the entire multitude of some whole which is itself always perfect to the same degree [semper aequaliter perfecti], exists always. But this is true of this thing, for . . . it does not exist except because its existence is good ... and it is good for the whole multitude of beings since the universe is an interconnected whole. . . . [Furthermore] the universe is always perfect. Therefore this thing will always be" Exigit (p. 186). From this it is clear that Nicholas sees the good of each individual thing as ordered to the good of the entire universe. As he believes that the universe has an unchanging degree of perfection, he concludes that no individual thing can be corrupted. If it were, he argues, the total good of the universe would itself be diminished. For an extended discussion of this proof, see Weinberg, Nicholaus of Autrecourt, pp. 127-48

10. For Nicholas's extended argument on this matter, see Exigit, pp. 198-200. 
but do not invoke the corruption of the quality itself. The most plausible of these, he believes, is the following: "Natural forms [e.g., the accidental form of whiteness] are divisible into minimum parts [minima] which, when divided off from the whole, cannot perform their proper action. And so, though they are seen when existing in the whole, they are not seen when dispersed and divided or separated." 11 That is, the smallest constituent parts of a natural form are sensible when existing collectively, but when separated from one another and existing individually they are insensible. So while the form ceases to appear, all of its constituent parts remain. And this, Nicholas believes, is sufficient to deny that any genuine corruption has taken place.

To clarify this argument we must note two things. First, although Nicholas uses the term 'minimum parts' (minima), he makes it clear elsewhere that the ultimate constituent parts of a substance and its accidents are atoms (atomalia). ${ }^{12}$ In light of his concern to defend the eternity doctrine, this is not at all surprising. The classical conception of atoms, of which Nicholas is an advocate, is one of bits of matter which are unchanging, indivisible, and indestructible-none of which can be said of minima. ${ }^{13}$ Second, Nicholas reduces those changes which Aristotle characterized as the generation and corruption of substances and their alteration through the generation and corruption of qualities to the locomotion (congregation and dispersal) of atoms. ${ }^{14}$ It is easy to see the

11. Nicholas, Exigit, p. 199.

12. For instance, in an attempt to make sense of the Aristotelian distinction between substance and accident, Nicholas writes, "There are [certain] atoms which are such that upon their departure [from the subject], what is called the operation of a thing no longer appears. .. . There are others which are such that upon their departure, [these operations] do not go away. And these latter ought more properly to be called the accidentals of a subject" (Exigit, p. 204). See also nn. 13 and 14.

13. Following Aristotle (Physics 187b14-22), medievals generally took minima as minimal homoeomeric parts sharing in the formality of that which they compose; for example, the minima of flesh are the smallest units into which flesh can be divided and remain flesh. That minimism was not really an option for Nicholas is clear from the fact that minima were themselves considered to be divisible and subject to loss of form when so divided. Any division of the minima of flesh would yield something which is not flesh. Because of this, minima were clearly part of the Aristotelian universe of generable and corruptible things. For a helpful discussion of the medieval doctrine of minima, see Norma Emerton, The Scientific Reinterpretation of Form (Ithaca, N.Y.: Cornell University Press, 1984), pp. 76-105.

14. Nicholas uses the terms 'generation' and 'destruction' when referring to the congregation and dispersal of atoms which constitute a substance, and he distinguishes these from that to which the term 'alteration' is appropriately applied: "When from some motion there follows a congregation of natural bodies which gather together and receive the nature of a subject, this is called generation. When they are separated, this is called destruction. When through locomotion there are joined to a certain subject atomic particles of such a kind that their arrival seems unrelated both to the movement of the subject and to what is called its natural functioning, that is called alteration" (Exigit, pp. 200-1). 
motivation behind this thought. Since locomotion involves no generation or corruption on the part of its subject, Nicholas believes that this reduction allows him to deny that change of any kind involves the generation or corruption of being. ${ }^{15}$ This is the key point which he wishes to put forth against Aristotle.

Before the objection from common experience is completely dismissed, however, Nicholas finds that he must address a potential problem concerning the ontology of motion. Immediately after invoking the dispersal of constituent atomic parts to explain the cessation of the appearance of a substance and its accidents, Nicholas admits that his reasoning "does not extend to motion, if motion is a thing distinct from the mobile, since unlike other natural entities, it does not consist of permanently existing atoms that can be dispersed." 16 That is, if motion is itself a thing distinct from the mobile, whether or not being is acquired or lost by or through it, it still poses a problem for the eternity doctrine since its acquisition or loss cannot be accounted for by the congregation or dispersal of atoms that compose it. In this case the acquisition or loss of motion by the mobile would appear to constitute, in direct violation of the eternity doctrine, the genuine generation or corruption of a thing. It is no surprise, then, that Nicholas concludes that he must "investigate whether motion is distinct from the mobile . . . before the end of the treatise." 17 In short, he must investigate the ontological status of motion.

Here Nicholas faces a choice. He must either construct a theory, in addition to atomism, which will explain why, if motion is a distinct thing, its acquisition and loss by the mobile does not constitute a genuine case of generation or corruption, or he must deny that motion is a thing distinct from the mobile. As we shall see, Nicholas opts for the latter alternative. In doing so he enters into the lively debate on this issue which had been raging among his colleagues at Paris and aligns himself with the Ockhamist camp. In the next two sections we shall investigate both the origins of this debate and Ockham's analysis of the problem. We shall then turn back to Nicholas and examine the way in which he appropriates Ockham's analysis.

15. There is, of course, a certain amount of ambiguity in this argument. At times Nicholas seems to assume that the dispersal of atoms that constitute a substance or accident does not constitute the corruption of that substance or accident because all of the substantial or accidental parts remain. Given this assumption, the eternity doctrine embraces the eternity of substances and their accidents. At other times, however, Nicholas seems to assume that while the substance or accident can be said to be corrupted through the dispersal of its constitutive atoms, this does not constitute genuine corruption (i.e., corruption of being) since those things which have being primarily are the incorruptible atoms. Given this assumption, the eternity doctrine embraces the eternity of atoms only.

16. Exigit, p. 200.

17. Exigit, p. 200. 


\section{MOTION AND THE CATEGORIES: A SCHOLASTIC PUZZLE}

The point of departure for a great many of the scholastic discussions of the ontological status of motion is a passage from the opening of the third book of Physics, in which Aristotle sets forth the relation of motion to the categories. ${ }^{18}$

No motion exists apart from things; for that which changes always does so either with respect to substance or with respect to quantity or with respect to quality or with respect to place, and there can be no thing common to these which is not ... a this [i.e., substance] or a quantity or a quality or some one of the other categories. Thus neither a motion nor a change can exist apart from these [categories] if nothing else exists but these. 19

Here Aristotle makes it clear that motion exists only with respect to the categories and cannot itself be considered a separate category into which its particular types fall. On reading this text, many of the scholastics argued that the basic types of change-generation and corruption, augmentation and diminution, alteration, and locomotion-are properly placed within the corresponding categories of substance, quantity, quality, and place. Because generation or corruption, for example, are motions with respect to substance, they fall in the category substance; similarly, for augmentation and diminution, alteration, and locomotion.

As tidy as it might be, however, this interpretation is clouded somewhat by an apparently conflicting passage from the Categories in which Aristotle cites the process of being heated as an illustration of the category of passion. ${ }^{20}$ This is particularly troublesome because this process is clearly an instance of alteration. As such, if we follow the interpretation given above, it should fall not in the category of passion but in the category of quality. This puzzled many of the schoolmen, who realized that if Aristotle was willing to treat alteration as a species of passion, other types of motion might be so treated as well. And if that were the case, there would seem to be direct conflict between what he says in Categories and what they took him to be saying in Physics. Thus, the schoolmen found themselves confronted with the double problem of harmonizing the Aristotelian texts both with one another and with what they considered to be the truth of the matter.

In working out this puzzle, many took their lead from some remarks made by Averroes. He, too, wondered about these problems and, in typical

18. The most comprehensive and authoritative discussion of the problem I treat in this section is to be found in Anneliese Maier, Zwischen Philosophie und Mechanik (Rome: Edizioni di Storia e Letteratura, 1958), pp. 61-143.

19. Aristotle Physics 200b33-201a2.

20. Aristotle Categories 11b1-8. 
scholastic fashion, tried to solve them by making a distinction. Commenting on Physics, he writes,

Motion, insofar as it does not differ from the perfection to which it proceeds [ad quam vadit] except according to greater and less, necessarily belongs to the genus of that perfection. For motion is nothing other than the generation, one part after another, of that perfection to which that motion tends until the perfection is reached and is in act. . . However, according as it is a process towards a perfection [via ad perfectionem] which is distinct from the perfection itself, it is necessary that it be in a genus perse, for a process to a thing is distinct from the thing itself. According to this view, then, motion must be posited as a category perse. And this way of speaking is more widely known, while the other is truer. Thus, Aristotle introduced this more widely known way in the Categories, and the other, truer way in this book [i.e., Physics]. ${ }^{21}$

Averroes claims that motion can be considered in two ways. First, it can be taken as the very form or perfection to which it tends, not insofar as that form is actualized in a subject at rest relative to it, but insofar as that form is progressively instantiated in its subject. Taken as such, motion must fall under the same category as its terminus ad quem since it is nothing but that terminus successively realized. Second, motion can be taken as the process itself by which the form is realized. Taken as such, it is distinct from its terminus and must be placed in a distinct category. 22

Now we must realize that in this commentary Averroes is not simply trying to answer an interpretative question. His identification of what he takes Aristotle's meaning to be in Physics as the 'truer way' clearly indicates his preference for identifying motion with its terminus and locating it within the categories of substance, quantity, quality, and place. In this Averroes was followed by many, though certainly not all, of the schoolmen. But no one was to push this interpretation further than William of Ockham, who wished to purge natural philosophy from any and all hypostasized concepts of motion. It is to his analysis that we now turn.

\section{OCKHAM, MOTION, AND THE PRINCIPLE OF PARSIMONY}

In the Tractatus de successivis, Ockham aligns himself with Averroes's reading of Physics and takes Averroes to have correctly understood that Aristotle did not in any way intend to posit motion as a thing distinct from permanent

21. Averroes, Commentary on Aristotle's Physics, bk. 3, c. 4, translated from the Latin text cited in Maier, Zwischen Philosophie, p. 5.

22. We should note that elsewhere in his Commentary (bk. 5, comment 9) Averroes identifies this category as the category of passion. See Maier, Zwischen Philosophie, pp. 64-67. 
things (res permanentes) -in this case, the mobile body and the term of its motion. ${ }^{23}$ To correct any possible misunderstanding, he writes,

In distinguishing two types of motion, [Averroes] does not mean that motion can truly be taken in two ways, as if in one way it is the terminus ad quem and in another it is the process differing from the terminus and the moveable body. . . . Rather, he intends to express two opinions concerning motion, of which one, the more famous, is false, and the other is true. ${ }^{24}$

In this passage Ockham aligns himself with what he considers to be integral Aristotelianism and takes aim at those who would posit motion as a process or thing distinct from the subject or the term of motion. Such people, he insists, are not only following the path of error but are straying from the teaching of the master as well. ${ }^{25}$ To correct these errors, Ockham sets forth his own analysis of motion, employing the full apparatus of his unique logical and epistemological doctrine.

Ockham begins his analysis by dividing all change into two types: immediate change (mutatio subita), in which form is acquired or lost in an instant, and successive change (motus successivus), in which form is acquired or lost successively. The first, which can be called motion only in a general sense ( $m o-$ tus large), includes generation and corruption; the second, which is motion in the proper sense (motus stricte), includes augmentation and diminution, alteration, and locomotion. Ockham then sets out to show that in neither case can motion be considered a thing distinct from its subject or its term. ${ }^{26}$ In

23. For a comprehensive analysis of the issues I treat in this section, see Herman Shapiro, Motion, Time and Place according to William Ockham (St. Bonaventure, N.Y.: Franciscan Institute, 1957), pp. 24-91.

24. Ockham Tractatus de successivis, ed. Philotheus Boehner (St. Bonaventure, N.Y.: Franciscan Institute, 1944), p. 49. This work is not included in the Opera Philosophica (hereafter OPh) of Ockham since it has been shown to be a compilation of excerpts from others of Ockham's works on natural philosophy. See Boehner's introduction to Tractatus.

25. The passage continues: "For some have said that motion is a thing differing from the terminus a quo, the moveable body, and the terminus ad quem. . . This was the more famous opinion at the time of Aristotle. . . The other was the true opinion of Aristotle himself" (Tractatus, p. 49).

26. In this context 'distinct from' refers to the real distinction, which, roughly speaking, is the distinction existing between two things which can exist apart from each other by the absolute power of God. The paradigm case of this distinction is that between substances (e.g., Socrates and Plato), but the distinction was also extended to that between matter and substantial form, as well as between substance and certain kinds of accidents. Marilyn McCord Adams sets out Ockham's criterion of the real distinction as follows: "If $x$ and $y$ are really distinct created real things, neither of which is part of the other, then it is logically possible that $x$ should exist without $y$ and logically possible that $y$ should exist without $x$." Here we should note that for Ockham the logically possible is coextensive with that which falls under the absolute power of God. For her discussion of the real distinction, see Marilyn McCord Adams, William Ockham (Notre Dame, Ind.: University of Notre Dame Press, 1987), pp. 16-19. 
what follows we shall pass over the discussion of immediate change and focus on Ockham's treatment of change that involves succession, particularly locomotion, since it is this analysis which Nicholas picks up and uses for his own purposes. Thus, when I use the term 'motion' from now on, I will be referring to motion in the proper sense.

To understand Ockham's analysis it will be helpful first to consider why those whom he takes as his opponents thought motion to be a thing distinct from its subject and term. The first consideration is quite simple. If two things are such that one remains while the other does not, they are really separable and, hence, really distinct from each other. But the subject and term of motion can remain after the subject ceases to move. Motion, then, must be really distinct from both. ${ }^{27}$ Second, we should also consider that the subject and term of motion are what were commonly classified by fourteenth-century scholastics as permanent things (res permanentes). That is, they are entities whose parts are able to exist simultaneously with one another and have duration. A substance, for example, which undergoes alteration from black to white, although undergoing change, nevertheless has all of the parts which constitute it as a substance at once; so, too, for the whiteness which is acquired by that alteration. It is clear, however, that if motion is a thing, it cannot be a thing of this kind since by its very nature its parts cannot exist simultaneously but exist one after another. Ockham's opponents concluded from this argument that motion must be distinct from all permanent things, its subject and term included, and must instead be considered a purely successive thing (res pure successiva). ${ }^{28}$

Ockham, of course, thought this position to be completely ludicrous. The very idea of a successive thing struck him as incoherent since he believed it to entail that a being can be composed of parts which are themselves nonbeings. His argument is simple. If motion is itself a successive thing divisible into parts which exist successively, for any motion which can be said to exist presently, each of its parts, except its present part, will be either prior or posterior to the present. But parts prior or posterior to the present cannot themselves be said to exist. Consequently, for any motion which can be said to exist presently, that motion is composed of parts which cannot be said to exist. As he took this to mean that motion is a being composed of nonbeings, Ockham concluded that the idea of a purely successive thing simply collapses into nonsense.

Ockham's argument here is really a reductio, designed to show the

27. This argument and the next are stated as objections to Ockham's answer to the following question: Utrum possit ratione sufficienti quod motus importet aliud a rebus permanentibus? See Ockham Questiones in libros physicorum Aristotelis, Q.17 OPh 6, p. 436.

28. For a defense of this position, see Walter Burleigh, In Physicam Aristot. Expositio et Quaestiones IIIt.11 (Venice 1501, ff.64rb-65vb); and Walter Chatton, Reportatio, 2.d.2, q. 1 (cod. Paris, ff.90rb-91va). 
absurdity of asserting motion to be a thing distinct from permanent things. ${ }^{29}$ If motion is such a thing, the argument goes, it can only be a successive thing. But the very idea of a successive thing is absurd. Therefore, and so on. Now the argument seems clear enough, but what about the thesis? If motion is not distinct from permanent things, does this mean that it is itself a permanent thing? Ockham's answer is that it does not. In his universe, only substances and qualities are permanent things, and motion is neither. As Ockham's analysis proceeds, then, it becomes quite clear that what is meant by this thesis is not that motion is itself a permanent thing but simply that one need not posit any other thing besides permanent things in order to account for it. To see how this works out, let us look at the following analysis of locomotion:

From the fact that a body is first in A, no other thing than A [and the body] is posited; similarly from the fact that that same body is not first in B, no other thing than B and the body is posited; and again, from the fact that that body is next in B, no other thing than B and the body is posited. And proceeding in this way with regard to other [places] it is clearly evident that besides a body and the parts of place and other permanent things, it is not necessary to posit another thing [to explain the locomotion of the body]. It is only necessary to posit that the body is at a particular time in this place . . and at another time it is not. 30

What we have here is a beautiful example of the way in which Ockham applies to a physical problem his famous principle of parsimony: frustra fit per plura, quod potest fieri per pauciora (it is vain to do through more what can be done through fewer). His point is to show that locomotion, in this case the motion of a body from place $A$ to place $B$, can be fully accounted for without positing anything other than permanent things, and certainly without positing motion as a distinct successive thing. For a body to be in locomotion, it is sufficient merely that it successively occupy different places, do so without resting in any of the intervening places, and do this continuously throughout the entire time it is consid-

29. Ockham's full argument is as follows: "If motion is a thing distinct from permanently existing things, it is either divisible or indivisible. But according to [my adversaries] it is not indivisible. Therefore it is divisible. Now it is either divisible by virtue of having simultaneously existing parts, in which case motion has length, breadth and depth, or by virtue of having parts which are not simultaneously existing. [My adversaries] concede the latter but not the former. But the latter cannot be said since that which does not exist cannot be a part of any existing being. This is because no being is composed from non-beings. Thus, it cannot be said that motion is some being other than permanent beings" (Summula philosophiae naturalis 3.5. OPh 6, p. 262).

30. Ockham, Tractatus de successivis, pp. 45-46. 
ered to be in motion. ${ }^{31}$ No entities other than the body and the places it occupies need be assumed, and to posit any would be superfluous. ${ }^{32}$ Ockham clearly wants to keep his ontology lean.

After driving this point home with numerous examples, Ockham turns to the source of our confusion concerning concepts such as motion. Not surprisingly, he locates it in confusions about language, ${ }^{33}$ and it is here that the underlying nominalism of his analysis of motion becomes clear. "It is imagined by many," he writes, "that just as there are distinct nouns, so also are there distinct things corresponding [to each of these nouns]." 34 This, he argues, is the source of a multitude of philosophical errors, including the majority of errors in physics. To avoid them, we must realize that many nouns are derived from verbs, adjectives, prepositions, and other parts of speech and do not signify anything other than the words from which they derive and the things signified by those words. Although such nouns can be useful for stylistic purposes, for the sake of either brevity or ornament, if we imagine that there is a distinct entity corresponding to each of them, we will be led to embrace an ontology made up mainly of hypostasized entities. To see the problem, consider the abstract noun 'simultaneity'. When used in the sentence 'There exists a simultaneity between $\mathrm{X}$ and $\mathrm{Y}$ ', this word seems to signify some entity distinct from $\mathrm{X}$ and $\mathrm{Y}$. But if we posit such an entity, we will be positing as real what is merely hypostasized, for 'simultaneity' only expresses the fact that $\mathrm{X}$ and $\mathrm{Y}$ exist simultaneously. And we need refer to no other entity besides $\mathrm{X}$ and $\mathrm{Y}$ to account for this fact. If we realize this, we can avoid positing an extraneous entity and keep our ontology lean.

Unfortunately, many of the abstract nouns derived from other parts of speech are much more misleading than is 'simultaneity' and can lead to

31. Ockham writes, "Locomotion is simply this: first to be in one place, without any other thing being posited; afterwards to be in another place, without any rest intervening and without any other thing besides the place, the body and other permanent things; and then to proceed continuously in like manner" (Tractatus de successivis, p. 46). This last phrase 'and then to proceed continuously in like manner' ( sic continue procendendo) is extremely important; it shows that Ockham considers motion to be continuous rather than discrete. See also Ockham Quaestiones in libros Physicorum Aristotelis Q. 22, OPh 6, pp. 452-53.

32. One may wonder whether Ockham is treating place here as a permanent thing that the mobile acquires and loses through locomotion. The answer is no, for Ockham follows Aristotle in defining place as the innermost surface of a containing body (see Physics 210b32-212a30) and argues that the surface of a containing body is not a thing really distinct from the body itself. From this he concludes that place is not a distinct entity in its own right. For a further discussion, see Shapiro, Motion, Time and Place, pp. 112-32.

33. For a detailed analysis of Ockham's application of his theory of language to his physics, see Stephen Brown, "A Modern Prologue to Ockham's Natural Philosophy," in Sprache und Erkenntnis im Mittelalter (Miscellanea Mediaevalia 13.1), ed. A. Zimmermann (Berlin: De Gruyter, 1981), pp. 107-29.

34. Ockham, Tractatus de successivis, p. 46. 
quite serious philosophical problems. For this reason Ockham believes that when doing philosophy it is better to avoid them altogether:

Because of the errors arising from the use of such abstract nouns, it would be better for the sake of simplicity in philosophy not to use them, but to use only verbs, adverbs, conjunctions, prepositions, and syncategorematics as they were primarily instituted. . . . Indeed, if it were not for the use of such abstractions as 'motion', 'change', 'mutability', 'simultaneity', 'succession', 'rest' and others of this kind, there would be few difficulties with respect to motion, change, time, instants and other things of this kind. ${ }^{35}$

In short, though abstract nouns may add to the richness of language, they can be lethal when doing philosophy.

Now what is interesting about this passage for our purposes is its identification of the term 'motion' as a derivative abstract noun, thus placing it on par with the term 'simultaneity'. Here, Ockham believes, lies the primary source of confusion. Those philosophers who posit motion as a thing distinct from permanent things are, to put it in Wittgensteinian terms, bewitched by language. Believing that there is a distinct thing corresponding to every distinct noun, they take the term 'motion' to signify a thing distinct from all other things signified by nouns not synonymous with it. Ockham contends, however, that the term 'motion' was not invented to signify distinct things but is employed for the sake of eloquence alone. Thus, we can not only express all of our concepts perfectly well without using it but also we would be better off if we abandoned its use altogether. All statements in which abstract nouns such as 'motion', 'succession', and 'rest' occur ought to be translated or resolved into statements that use such terms or expressions as 'it moves', 'it succeeds', and 'it rests'. ${ }^{36}$ Carrying this resolution out, Ockham concludes,

This proposition 'motion is' does not denote that there exists some thing signified through the term 'motion' which is distinct from all other things, but rather [the following proposition] is understood: 'That which is moved has some part and without intervening rest it will have other parts of the same kind'. And from these it does not follow that motion is something other than permanent things, but it follows that that which is moved will have some permanent things beyond those which it now has. ${ }^{37}$

35. Ockham Tractatus de successivis, p. 46-47.

36. Ockham writes, "Propositions in which such words as 'motion' [motus], 'movement' [motio], 'succession' [successio] 'successive thing' [successivum] and other words of this kind are used ought to be resolved into propositions in which such words as 'it is moved' [ movetur], 'the moved' [motum], 'it succeeds' [succedit], 'succeeding thing' [succedens], and other words of this kind are posited" (Summula philosophiae naturalis $3.7 \mathrm{OPh} 6$, p. 267).

37. Ockham Questiones in libros physicorum Aristotelis Q. 17, OPh 6, p. 438. 


\section{NICHOLAS AND THE OCKHAMIST ANALYSIS OF MOTION}

Here we need only recall the problem with which we concluded our initial discussion in order to see why Nicholas would find Ockham's analysis attractive. In his attempt to dispense with the objection to the eternity doctrine from common experience, Nicholas had either to explain why, if motion is a distinct thing, its acquisition or cessation does not constitute genuine generation or corruption or to deny that motion is a distinct thing. Following Ockham's lead, Nicholas follows the second path. Two considerations will be sufficient to see this choice.

In the section of the Exigit devoted to motion, Nicholas announces that he is primarily interested in investigating whether motion (by which he means locomotion) is a thing distinct from the movable object. He begins with the following observation: "It must be noted that, as someone says, these names 'motion' [ 'motus'] or 'movement' ['motio'] were invented only for ornamentation. Hence, if the propositions in which such names are placed were resolved into their verbs, many difficulties, whether nominal or real, would cease." 38 This should now sound entirely familiar. Like Ockham, Nicholas sees many of the problems surrounding motion as being due to the insufficient attention philosophers pay to the diverse modes of linguistic expression. More precisely, he locates the confusion concerning the ontological status of motion as stemming from the fact that the noun 'motion' is a kind of shorthand for a set of propositions, none of which imply that motion is an entity. To say, for example, that a being has local motion is really to say that a being moves locally, which in turn implies the following three propositions:

(1) Between this body and some place there was previously an intervening space.

(2) There is now an absence of an intervening space between this body and that place.

(3) Now that this body is related to that place by an absence of an intervening space, the parts of a contradiction [i.e., there is and is not an intervening space between this body and that place] cannot be verified. 39

38. Exigit, pp. 223-24.

39. For the sake of greater consistency, I have slightly modified Nicholas's wording of these statements by substituting 'place' for 'body' in the first statement. The text reads as follows: "Hence, to say 'This being is moved locally' is the same as to say all of the following: 'Between this body and another there was previously an intervening space [medium]; now there is a negation of the intervening space; and, now that the body is related to some place by the negation of the intervening space, the parts of a contradiction cannot be verified'" (Exigit, p. 224). 
Nowhere in these statements is motion posited as a positive entity distinct from and inhering in the moving object. All that is posited is the movable body, the places it occupies, and the negation of an intervening space. Anything else is superfluous. 40

Lest anyone still believe, however, that motion is a positive entity, Nicholas issues the same charge as does Ockham. If motion is a positive entity, it must be a successive entity, but to assert that it is a successive entity is to assert something unintelligible.

I do not clearly understand, what my opponents mean by 'successive being' unless they wish to say that for a successive being it suffices that there be a nonbeing. But it does not seem intelligible that some positive entity exist, and yet be composed of two parts of which it is true to say of one that it has passed and is a non-being and of the other that it will be in the future and is a non-being. ${ }^{41}$

In short, Nicholas finds the same problem with the doctrine of successive being as does Ockham; it presupposes the absurd notion that a being can itself be composed of nonbeings and winds up in utter incoherence.

With these two Ockhamistic lines of attack, Nicholas dismisses the view that motion is a positive thing which is both inherent in the mobile and distinct from it. This is of crucial importance because it affords him an answer to the reformulated objection to the eternity doctrine. In short, the cessation of motion cannot be counted as a cessation of the existence of any positive or absolute entity. So if one asserts that motion is destroyed when a thing comes to rest after having moved, the only meaning that one can assign to this assertion which renders it true is that the movable object, which previously was moving, is now not moving. But this, as Nicholas points out, "can be so without the corruption of some positive entity." 42

It is clear, then, that Nicholas's use of Ockham's analysis gave him a convenient way of salvaging his eternity doctrine-the centerpiece of his anti-Aristotelian attack-in the face of the objections drawn from common experience. But we must remember that Ockham's analysis was neither developed for this purpose nor part of a larger atomistic theory of motion. Ockham, as he stressed over and over, wished to give an account of motion in accordance with the intention of Aristotle (de intentione Aristotelis). It is at least a small irony, then, that this very account could be pressed into service as part of what was perhaps the most vehement attack on Aristotelianism in the Middle Ages. Yet beyond whatever irony we may find in this situation, there is an interesting philosophical question. In looking at Nicholas's use of Ockham, we might ask whether we find a merely accidental relation of

40. Nicholas writes, "I posit no such thing because it is not necessary, as has been seen, nor even very intelligible" (Exigit, p. 224).

41. Exigit, p. 224.

42. Exigit, p. 225. 
nominalism and atomism or whether some real philosophical kinship between the two is there displayed. In other words, should we see Nicholas's adoption of the nominalist ontology of motion merely as a convenient strategy by which to salvage the eternity doctrine, or should this alert us to some intrinsic connection between atomism and nominalism of which Nicholas may have been aware and which explains his reliance on Ockham? It is to this question that we now turn.

\section{ATOMISM AND NOMINALISM}

In section I, I claimed that Nicholas's doctrine of motion (of all sorts) must ultimately be understood in terms of atomism rather than minimism. This is important, for medievals generally understood minima naturalia on the hylemorphic model of material substance as form-matter composites. As such, they were thought to be both susceptible to further division (though they lose their form through such division) and capable of being subjects of any number of qualities distinct from, yet inhering in, them. Nicholas, however, aligned himself with the Democritean tradition in which the ultimate constituents of material substances are taken to be atoms. ${ }^{43}$ Unlike minima, Democritean atoms are supposed to be absolutely simple entities incapable of physical, and possibly even theoretical, division. ${ }^{44}$ More important, they are not supposed to have any manner of composition.

The doctrine of atomic simplicity, however, does not mean that atoms are devoid of a plurality of properties. If we can trust Aristotle's account, Democritus considered his atoms to be in ceaseless motion and to possess a variety of sizes and shapes. ${ }^{45}$ Indeed, this variety is essential to the atomic theory, for atomists believed that the particular properties of diverse material bodies could not be explained merely by the diverse arrangements of their

43. This is the variety with which we should be most concerned since most of what the medievals knew about atomism came from Aristotle's several discussions of Democritus. For excellent general discussions of Democritean atomic theory, see W. K. C. Guthrie, A History of Greek Philosophy, vol. 2 (Cambridge: Cambridge University Press, 1965), pp. 389-99, and Richard McKirahan, Jr., Philosophy before Socrates (Indianapolis: Hackett, 1994), pp. 303-43.

44. It is a matter of scholarly debate whether Democritus took atoms to be theoretically indivisible. For authoritative discussions of this issue, see Guthrie, History of Greek Philosophy, pp. 503-7; David Furley, The Greek Cosmologists, vol. 1 (Cambridge: Cambridge University Press, 1987), pp. 124-31; and Jonathan Barnes, The Presocratic Philosophers (London: Routledge \& Kegan Paul, 1982), pp. 352-60.

45. See Aristotle's account in Metaphysics 985b4; Physics 203a33, and On the Heavens 303a11-15. We might also note the famous claim by Aetius that "Democritus specified two <basic properties of atoms >: size and shape; and Epicurus added weight as a third" (DK 68A47). Quoted from McKirahan, Philosophy before Socrates, p. 308. 
constituent atoms; a diversity among atomic properties is needed as well. Insofar as this is the case, I believe, atomism is bound not only to an essentially nominalistic ontology of the macroproperties of material bodies but to a nominalistic ontology of the microproperties of individual atoms as well. The necessity of this becomes clear if we simply keep in mind that the atomist, unlike the minimist, cannot take these microproperties to be in any way distinct from the atoms in which they inhere. To do so would be to abandon the doctrine of atomic simplicity. Thus, if the atomist is to give an account of atomic properties, he or she must do so in a way which posits no distinction between those properties and the atoms themselves. Before turning back to the question of the status of motion, I will try to cash out this claim by a brief examination of Ockham's and Nicholas's treatment of the properties of dimensive quantity and shape. In this we shall see Nicholas's adaptation of Ockham's nominalism as a necessary corollary to his atomism.

\section{NOMINALISM AND ATOMIC SIZE}

Central to the atomist's position is the claim that atoms, unlike mathematical points, possess some determinate size or spatial magnitude. From the Aristotelian perspective, one would say that they have, as do the material bodies they compose, continuous quantity. But what, we might ask, is the ontological status of continuous quantity? The answer one gets, of course, depends on whom one asks. For example, because continuous quantity falls in the general category of quantity, which is itself a category distinct from that of substance, it was tempting for a great many of the medievals to treat it as an accident distinct from the body in which it inheres. ${ }^{46}$ Whatever falls in some one category, in this view, is a thing distinct from that which falls in some other category. Such a view, it seemed to many, was not only the most natural way of interpreting Aristotle's categoreal scheme but also was reinforced by the observation of such phenomena as rarefaction and condensation, in which quantity was observed to be generated or corrupted but not the underlying substance itself. 47

Not surprisingly, this ontology was completely unacceptable to Ockham. Against it he maintained that the distinction among categories does not

46. Aquinas and Scotus are two of the most prominent figures who held that continuous quantity is a thing really distinct from substance and its qualities. Anneliese Maier, however, has argued that Ockham is responding not so much to them as to the arguments of Richard Middleton. See her exhaustive analysis of this entire problem in "Das Problem der Quantität oder Räumlichen Ausdehnung," in Metaphysiche Hintergrunde der Spätscholastischen Naturphilosophie (Rome: Edizioni di Storia e Letteratura, 1955), pp. 141-224.

47. For a discussion of the debate over rarefaction and condensation, see Adams, William Ockham, pp. 178-86. 
necessarily correspond to a distinction among kinds of things but corresponds instead to a distinction among kinds of names and modes of signification. The same thing, he argued, may be signified by categorically different names, each of which signifies in a different way or by a different modus significandi. 48 Thus, the term 'quantity' need not signify a distinct thing from that which the term 'substance' signifies. "I maintain that substance ... and quantity are distinct categories, although 'quantity' does not signify any absolute thing distinct from substance.... For they are distinct concepts and spoken sounds that signify the same things in different ways; and because they signify them in different ways, they are not synonymous names." 49 Ockham elaborates, explaining that 'substance' signifies both the substance and its parts directly, whereas 'quantity', while signifying the substance directly insofar as it connotes that the parts of the substance are locally distant from one another, signifies these parts obliquely. In a well-known passage from the Summa totius logicae, Ockham spells out the consequences. Continuous permanent quantity, he writes, is "nothing other than a thing having part locally distant from part [res una habens partem situaliter distantem a parte] ... [so that] these two phrases 'continuous permanent quantity' and 'thing having part distant from part' are equivalent in signification." ${ }^{0}$ Here the thing is signified directly through the use of the nominative case (res), whereas its parts are signified obliquely as being locally distant from one another through the use of the accusative and ablative cases (partem and a parte). In no way, then, is continuous quantity signified as a distinct thing from that in which it inheres.

Ockham's concern for a lean ontology here is shared by Nicholas, who repeats his arguments concerning quantity almost verbatim. "It does not follow," Nicholas writes, "that because there are ten concepts [i.e., categories], therefore there are ten things of which there are first these concepts." ${ }^{51}$ These concepts may all signify the same thing. Thus, in answer to the question of whether material substance simply is continuous permanent quantity, Nicholas replies, "On the thing considered in itself or as related to what are called its operations, the name 'substance' is imposed. But on

48. Here Ockham has in mind the difference between the way in which absolute and connotative terms signify. An absolute term signifies its object directly without indirectly signifying anything else, whereas a connotative term signifies both its object directly and something else indirectly. For example, the absolute term 'whiteness' signifies only the color, whereas the connotative term 'white' directly signifies the thing that is white while also connoting its whiteness. Clearly Ockham takes 'quantity' as a connotative term, which signifies a substance or quality directly and connotes that their parts exist in a certain way. 'Substance', on the other hand, is an absolute term. For further discussion of absolute and connotative terms, see Adams, William Ockham, pp. 319-27.

49. Quodlibeta septem 4. q.27. OTh 9, p. 436.

50. A few lines down, Ockham concludes, "And thus, when a substance has part locally distant from part, and similarly for a quality, then some quantity will not be another thing from a substance, and some quantity will not be other than a quality" (Summa totius logicae), 1.44. OPh 1, p. 137).

51. Exigit, p. 226. 
the same thing as having part outside of part [partem extra partem], the concept of quantity is imposed." 52 The relevant distinction, then, is not a distinction among things but between the modus significandi belonging to each term.

In making this claim, Nicholas shows himself a thoroughgoing Ockhamist concerning the relation of quantity to material substance. Indeed, there is good reason for this, for what other ontology of quantity could an atomist embrace? Insofar as a material body is composed of spatially extended atoms, it will itself be extended precisely in the sense of having part distant from part. If one were to explain this extension by positing the addition of some distinct property or accidental form of quantity, one would either have to suppose this property or form to be something other than a collection of atoms or not. In the first case, the ontology of atomism is compromised; in the second, one simply lapses into incoherence. To avoid these consequences, the atomist must embrace a nominalist ontology of quantity with respect to the macroproperties of bodies.

The more interesting issue, however, may be that of the ontology of the microproperties of atoms. How, for example, must the atomist view the spatial magnitude of the atom itself? Nicholas gives us no answer, but it is reasonable to suppose that he would continue to toe the Ockhamist line, for it yields the only result compatible with his atomism, namely, the denial of a distinct status for quantity. But here there is an obvious problem. Ockham's claim that 'continuous permanent quantity' directly signifies a thing and obliquely signifies its parts as locally distant from one another implies that that which is signified by the term 'quantity' has parts. This does not seem terribly promising for those who would wish to hold on to the doctrine of atomic simplicity.

Perhaps this may not be so serious a problem as it first appears. Insofar as atoms have spatial magnitude, there must be some sense in which they have parts locally distant from parts, even if these are only theoretical parts. At the very least, every section of the surface of an atom (however one might divide it) must be considered locally distant from every other section of that surface. ${ }^{53}$ As long as atoms are not taken to be mathematical points, it is hard to see how an atomist could deny this. Even Epicurus, the great defender of atomism against Aristotle, saw the need to posit minimum parts into which atoms could be theoretically divided in order to account for the fact of variation among the sizes and shapes of diverse atoms. ${ }^{54}$ Such parts, he argued,

\section{Exigit, p. 226.}

53. This may seem odd given that some or all of these parts would be contiguous with one another. But here we must remember that to say that a thing has parts locally distant from parts simply means that it has parts outside of parts (partes extra partes). Contiguous parts of the surface of an atom would certainly be outside one another.

54. For relevant excerpts from Epicurus's Letter to Herodotus concerning the doctrine of minimum parts, as well as commentary on those excerpts, see A. A. Long and D. N. Sedley, The Hellenistic Philosophers, vol. 1. (Cambridge: Cambridge University Press, 1987), pp. 39-44. See also Cyril Bailey, The Greek Atomists and Epicurus (Oxford: Clarendon Press, 1928), pp. 284-89. 
are of an invariant magnitude such that a lesser magnitude cannot be conceived. So while there is a lower limit to their theoretical divisibility, insofar as atoms are not themselves minimum magnitudes, they can in theory be divided. Given this one, seemingly necessary modification of the doctrine of atomic simplicity, Ockham's ontology of quantity not only appears to be compatible with atomism but also to provide the only viable account of atomic size.

\section{NOMINALISM AND ATOMIC SHAPE}

However successful a nominalist analysis may be in accounting for the property of size, it is not immediately clear that it can successfully be extended to account for the property of shape. Shape, according to the Aristotelian schema, falls not in the category of quantity but in that of quality. Though Ockham denies that the distinction between quantity and substance corresponds to a distinction among things, he makes no such denial concerning quality: "There are certain things in the genus of quality which constitute distinct things from a substance [quae important res distinctas a substantia] ... just as 'whiteness' and 'blackness', 'color', 'knowledge', 'light', and things of this kind are not [substances]." 55 Nevertheless, Ockham exempts shape from this list, denying that there is a real distinction between it and the subject in which it inheres. His reasons for doing so, I believe, are most helpful in understanding the appeal which nominalism might have for an atomist.

In the course of elaborating his criterion for distinguishing qualities which are distinct things from those which are not, Ockham writes, "In order to know when a quality must or must not be posited as a thing other than a substance, it is convenient to use this method: when some predicables can be successively, but not simultaneously, verified of the same thing due to locomotion alone, it is not necessary that these predicables signify distinct things." 56

What Ockham is doing here is limiting a general criterion of distinction. Generally speaking, he believes that if two predicables can be successively, but not simultaneously, verified of the same thing, they can be verified of that thing only through the generation of one and the corruption of the other. ${ }^{57}$ Thus, they must be distinct both from one another and from that of which they are predicated. ${ }^{58}$ In the passage just cited, however,

55. Ockham Summa totius logicae 1.55. OPh 1, p. 180.

56. Ockham Summa totius logicae 1.55. OPh 1, p. 180. See also Quodlibeta septem 7, Q. 2. OTh 9, pp. 706-9.

57. We may put this as follows: For any two statements of the form ' $\mathrm{S}$ is $\mathrm{P}$ ' and ' $\mathrm{S}$ is $Q$ ', if such statements can be true successively but not at the same time, they can only be true if $P$ is destroyed and $Q$ is generated or $Q$ is destroyed and $P$ is generated.

58 . Here we need only remember that a real distinction exists between any two things that can exist apart from each other by the absolute power of God. 
Ockham limits the scope of this criterion by arguing that in some cases predicables which are not simultaneously verifiable may be successively verified by the locomotion of the substance as a whole or by its parts. In these cases, no generation or corruption need be posited, nor should one posit any distinction between the predicables and the subject of predication. This, he believes, is particularly clear in the case of shape.

Consider a straight line which becomes curved. Surely, Ockham argues, one need not posit the destruction of some distinct quality, rectilinearity, and the generation of another, curvilinearity, to explain this change. One need only posit the locomotion of the parts of the line, namely, a motion by which the parts become closer to one another. And since we have already seen that nothing is generated or corrupted in locomotion, the qualities which stand as the termini of the motion (rectilinearity and curvilinearity) need not be posited as distinct from the subject in which they inhere.

It is obvious that this analysis would be attractive to atomists, for they would be the first to agree that shape is not to be explained by the inherence of some quality distinct from the body which is shaped. To posit distinct qualities in order to account for either atomic shape or the shape of a composite body would require them to introduce extra-atomic entities into their ontology-a move they would surely reject. Furthermore, atomists would find themselves in agreement with Ockham's explanation of alteration with respect to shape by way of the rearrangement of the constituent parts of a body since this is the very explanation they put forward to explain all forms of alteration, including change of color, temperature, and even states of the soul. Hence we find Aristotle commenting that "Democritus and Leucippus, having got the figures [i.e., the diversely shaped atoms], get alteration and generation from these: generation and corruption by their aggregation and segregation, alteration by their arrangement and position." 59 Certainly this extends explanation via the locomotion of parts much further than Ockham takes it, but it nevertheless exhibits much of the spirit that we find in his writings. In this way one can see atomism, at least in its account of qualities, as not only aligned with but also as a more radical form of the nominalism which Ockham develops. It is no wonder, then, that in mounting an atomistic challenge to Aristotle, Nicholas would find Ockham's work so congenial.

\section{NOMINALISM AND ATOMIC MOTION}

We are now in a position to complete our discussion of the ontology of motion. Up to this point we have focused on Nicholas's account of the

59. Aristotle, On Generation and Corruption 315b6-8, trans. C. J. F. Williams (Oxford: Clarendon Press, 1982). 
motion of complex bodies and have seen how that account is used to solve problems with the eternity doctrine. But now, so that we may extend the results of the previous two sections, we turn to the ontology of the motion of atoms themselves.

This problem is directly analogous to the one we encountered in our discussion of dimensive quantity. In the universe of the classical atomist, all that exists are atoms and the void through which they move. ${ }^{60}$ Thus, if motion were a thing distinct from the individual atoms which are in motion, it must itself be an atom or a composite of atoms. Nicholas, as we have already seen, rejects the suggestion that motion might itself be a composite of atoms. Though he does not explain himself, it is not difficult to see why he would do this. If the motion of an atom or a composite body were itself a distinct entity comprised of either one or more atoms, we could ask if it is itself in motion when the atom or body whose motion it constitutes moves. If we affirm that it is (and it would be ludicrous to suggest otherwise), we are immediately caught in a regress. If the atom or atoms constitutive of the motion of some atom or body are themselves in motion, there would be no reason not to take that motion to be a distinct entity as well. Presumably, then, we would have to explain that motion by way of other atoms, and the same difficulties would simply reappear. Thus, at some point, the atomist must deny the assumption that is driving the regress, namely, that motion is an entity distinct from the mobile body. In short, if the atomist is to avoid a regress in the explanation of motion on either the micro- or macrolevel he or she will have to embrace a nominalist ontology. Even apart from his concern to counter objections to the eternity doctrine, then, there now appears to be good reason for Nicholas to embrace Ockham's analysis of motion as a way in which to couch his own atomistic theory of motion. And if pressed, he most likely would have extended that analysis to explain the motion of individual atoms themselves. Once again, nominalism appears to lend the atomistic ontology greater coherence and completeness.

\section{CONCLUSION}

We may now take inventory of some results. First, we have placed Nicholas in the context of scholastic debates concerning the ontology of motion and have demonstrated his alignment with Ockham. In itself, this is of interest since Ockham thought his analysis of motion to be in complete agreement with the mind or intention of Aristotle. Yet Nicholas was able to use that

60. Nicholas, we should note, does not posit a vacuum separatum but a vacuum inceptum. In this, he departs from the Greek atomists, who posited a separate void through which atoms move. Here the authority of Aristotle seems to have held at least partial sway over Nicholas's thought. See Grant, Much Ado about Nothing, pp. 74-77. 
analysis to shore up problems with his eternity doctrine and its accompanying atomistic worldview, both of which were constructed with the explicit aim of showing views directly opposed to those of Aristotle to be more probable than those which Aristotle purportedly demonstrated. If we take scholasticism to be inextricably tied to Aristotelianism, we may see some justification here for the often repeated charge that Ockhamism was the fertile ground from which those forces destructive of scholasticism grew.

Second, though Nicholas's adoption of Ockham's analysis was introduced to resolve problems with the eternity doctrine, its more fundamental connection to his atomism is now apparent. As I have argued, in order to give a coherent account of both the macroproperties of bodies and the microproperties of atoms, atomists must either adopt a nominalist ontology of properties or compromise their atomism by positing nonatomic entities. Nicholas's writings present a clear picture of how the former works out in the case of motion and quantity. And though he does not address the case of shape, it is easy to complete the picture by examining Ockham's remarks concerning change with respect to quality. So while we may not rank Nicholas as one of the great constructive philosophers of the Middle Ages, we must nevertheless consider his advocacy of atomism amid the controversies over Ockhamism at Paris fortuitous insofar as it allows us to see this philosophical kinship of nominalism and atomism. For this reason his work deserves much greater attention than it has received. 
